\title{
REDUÇÃO DAS PERDAS NO VAZAMENTO CONTÍNUO DE CHAPAS DE ALUMÍNIO*
}

Francisco de Paula Pinheiro ${ }^{1}$ Thomas Santos Silva ${ }^{2}$

\section{Resumo}

Estudo das fontes de variação do processo de vazamento contínuo de chapas de alumínio, através da aplicação de uma metodologia prática e rápida para solução de problema. Após identificação das variáveis críticas à qualidade, ações foram tomadas de modo a minimizar as perdas do processo, o que contribuiu para a redução nos custos de produção das chapas.

Palavras-chave: Controle estatístico do processo; Vazamento contínuo; Rendimento metálico; DMAIC.

\section{SCRAP REDUCTION IN CONTINUOUS CASTING OF ALUMINUM STRIPS Abstract \\ A study of continuous casting and its process variation sources through a practical methodology of problem solving. After identifying variables critical to quality, a plan of action was done in order to minimize process losses and reducing production costs. Keywords: Statistic process control; Continuous casting; Metal recovery, DMAIC.}

1 Engenheiro Metalurgista, Consultor de Engenharia, Depto. Tecnologia, Votorantim Metais, Alumínio, SP, Brasil.

2 Engenheiro Metalurgista, Coordenador de Produção, Depto. Fundição, Votorantim Metais, Alumínio, SP, Brasil. 


\section{INTRODUÇÃO}

Devido ao nível de competitividade global mais acirrado do que nunca, as indústrias têm procurado melhorar cada vez mais os níveis de excelência operacional em seus processos.

Na Votorantim Metais (VM), a gestão por processos é um dos pilares de gestão da empresa, e a redução de perdas nos processos é uma das estratégias mais adotadas, uma vez que tem impacto direto no custo de produção, e consequentemente na rentabilidade.

A metodologia normalmente empregada na VM em projetos de melhoria é o ciclo DMAIC, proveniente da filosofia Seis Sigma [1], que compreende as etapas de Define, Measurment, Analyze, Improve e Control.

$\mathrm{Na}$ Companhia Brasileira de Alumínio (CBA) - principal unidade fabril da VM grande parte da matéria-prima utilizada na laminação vem do vazamento contínuo de chapas de alumínio, processo que combina solidificação e laminação numa única etapa [2]. As entradas e saídas do processo estão representadas pela Figura 1.

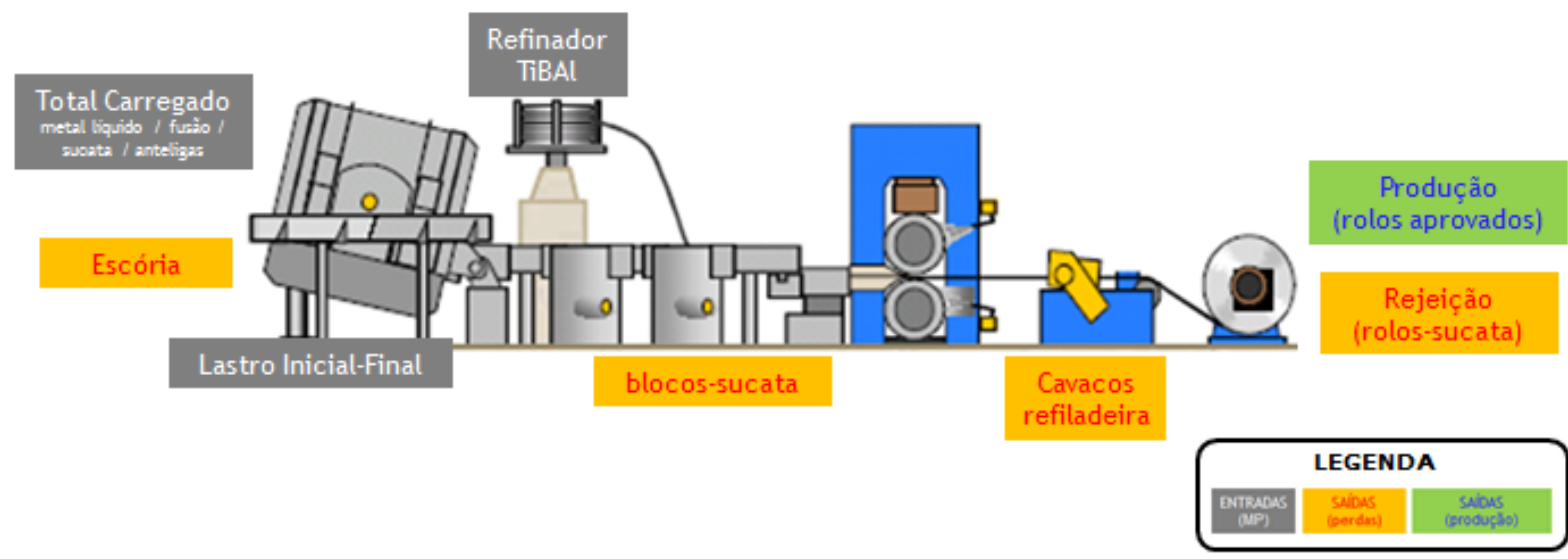

Figura 1. Representação esquemática do vazamento contínuo de chapas de alumínio com ênfase para as entradas e saídas do processo.

O foco principal deste trabalho foi aumentar o Rendimento Metálico (RM) - um dos indicadores mais importantes do processo - através da redução na quantidade de rolos sucatados. O RM é calculado através da razão entre o volume de produção e total carregado, portanto, quanto mais alto ele for, menor a quantidade de sucata (perdas) gerada no processo.

\section{MATERIAIS E MÉTODOS}

A metodologia está dividida em 5 seções: definição do problema, medição, análise melhoria e controle.

Para análise dos dados, foram utilizadas ferramentas teste de normalidade, teste de hipótese 2 sample-t. As análises gráficas tais como Pareto, histograma e carta de controle, também foram utilizadas para representar os dados e sustentar as conclusões. Todo tratamento dos dados e análises foram realizadas através d software de análises estatísticas Minitab. 


\subsection{Definição}

Para uma abordagem rápida e prática, o escopo do trabalho foi restringido aos casters largos, pois são responsáveis por mais da metade da produção total.

\section{Produção Casters 2013 \\ (\% vol sobre total)}

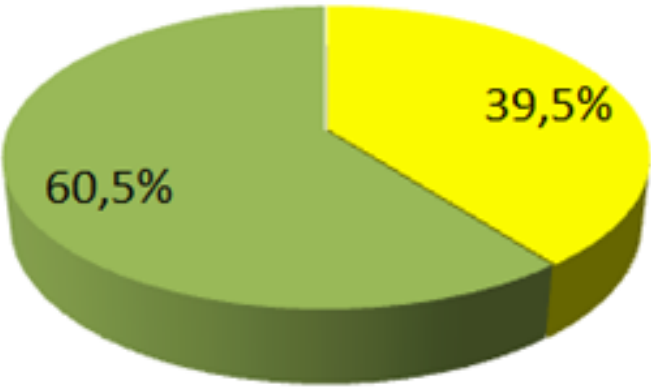

$$
\begin{aligned}
& \text { Casters } \\
& \text { Estreitos } \\
& \text { Casters } \\
& \text { Largos }
\end{aligned}
$$

Figura 2. Mix de produção nos casters da CBA

A partir disso, foram definidas meta e equipe, bem como a governança do projeto.

\subsection{Medição}

Realizado teste de normalidade para avaliar se o RM dos casters seguia uma distribuição normal e, em seguida, estudo estatístico para avaliar a capabilidade inicial do processo.

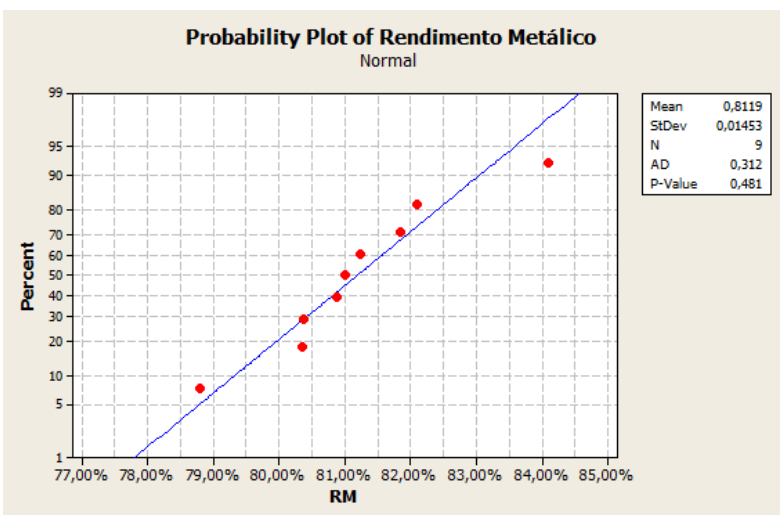

(a)

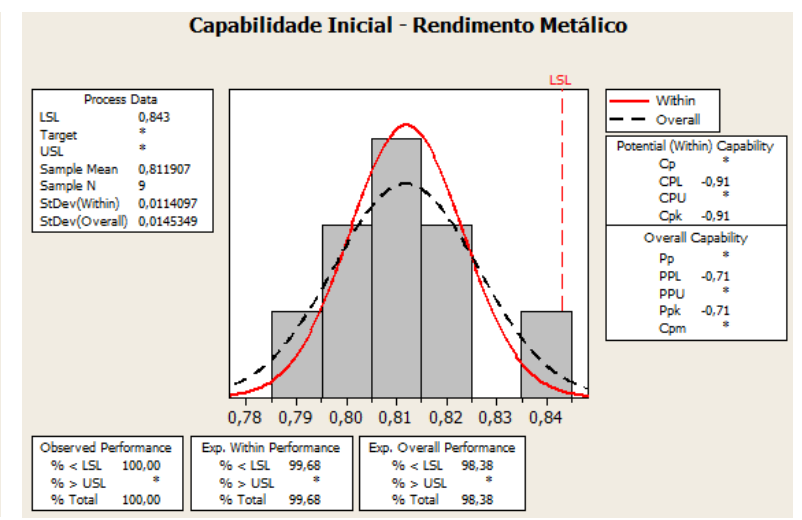

(b)

Figura 3. Estudo inicial do processo: teste de normalidade (a) e capabilidade de processo (b).

Após isso, o mapa do processo foi montado e foram levantadas todas as possíveis variáveis que pudessem ter impacto no RM. Estabelecido plano de coleta de dados, para identificar os motivos de sucateamento de rolos durante o processo, sendo apresentado graficamente na forma de Pareto.

\subsection{Análise}

Os motivos para sucateamento de rolos foram priorizados, e as quatro principais causas foram selecionadas para avaliação das causas-raiz com auxílio da ferramenta árvore de falha. 


\subsection{Melhoria}

Após identificação das causas-raiz a serem atacadas, um plano de ações para melhoria do RM foi definido. Após um total de 23 ações, realizamos teste de hipótese 2-sample-t para avaliar estatisticamente se houve ou não mudança significativa no rendimento metálico.

\subsection{Controle}

Para garantir a sustentabilidade das ações de melhoria, foi estabelecido um plano complementar para manutenção das ações implementadas.

\section{RESULTADOS E DISCUSSÃO}

A Figura 4 mostra o Pareto realizado para priorizar os motivos mais relevantes para sucateamento de rolos.

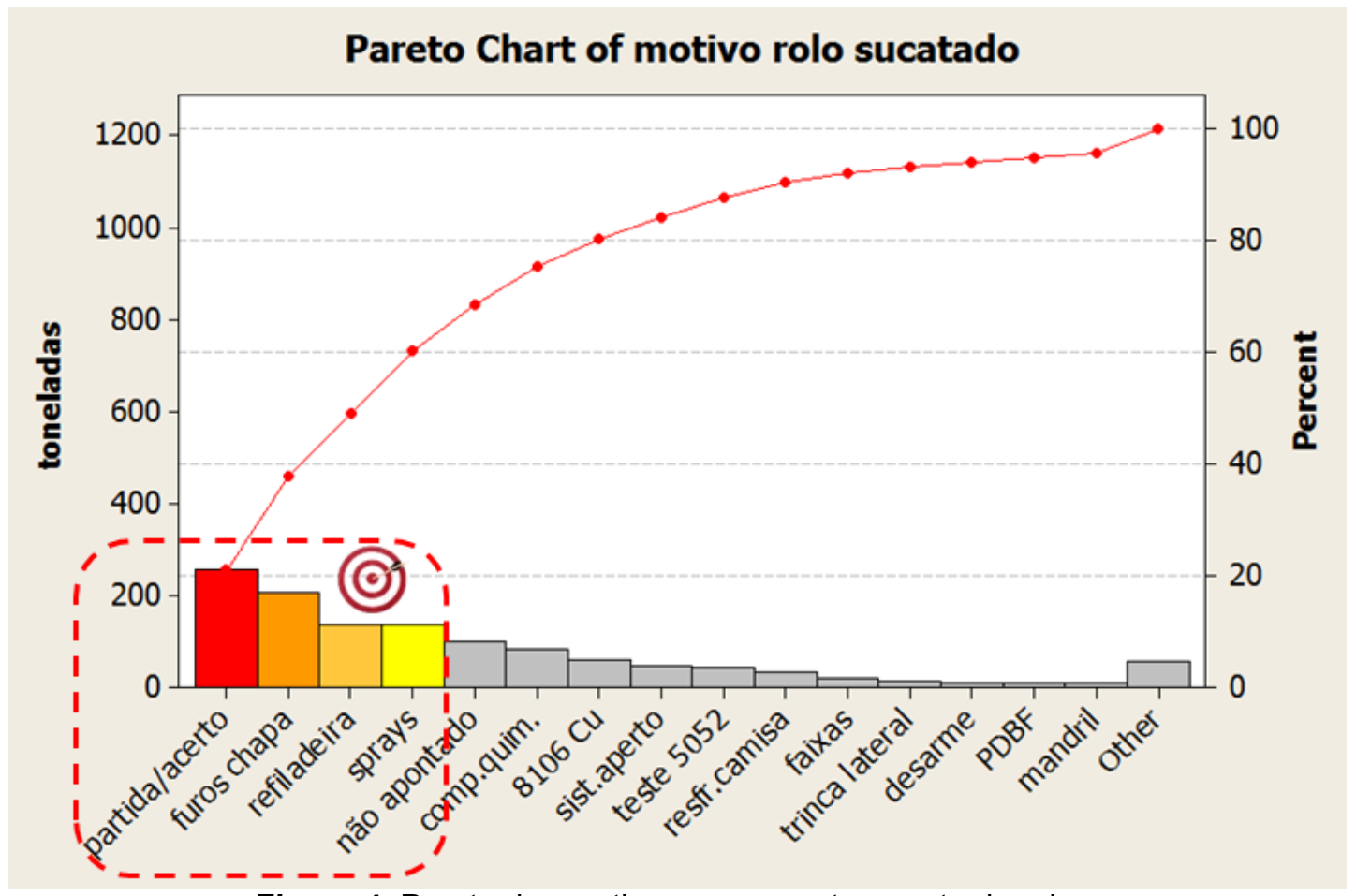

Figura 4. Pareto dos motivos para sucateamento de rolos.

E na Figura 5 estão os diagramas de árvore de falhas para cada um dos motivos priorizados. 

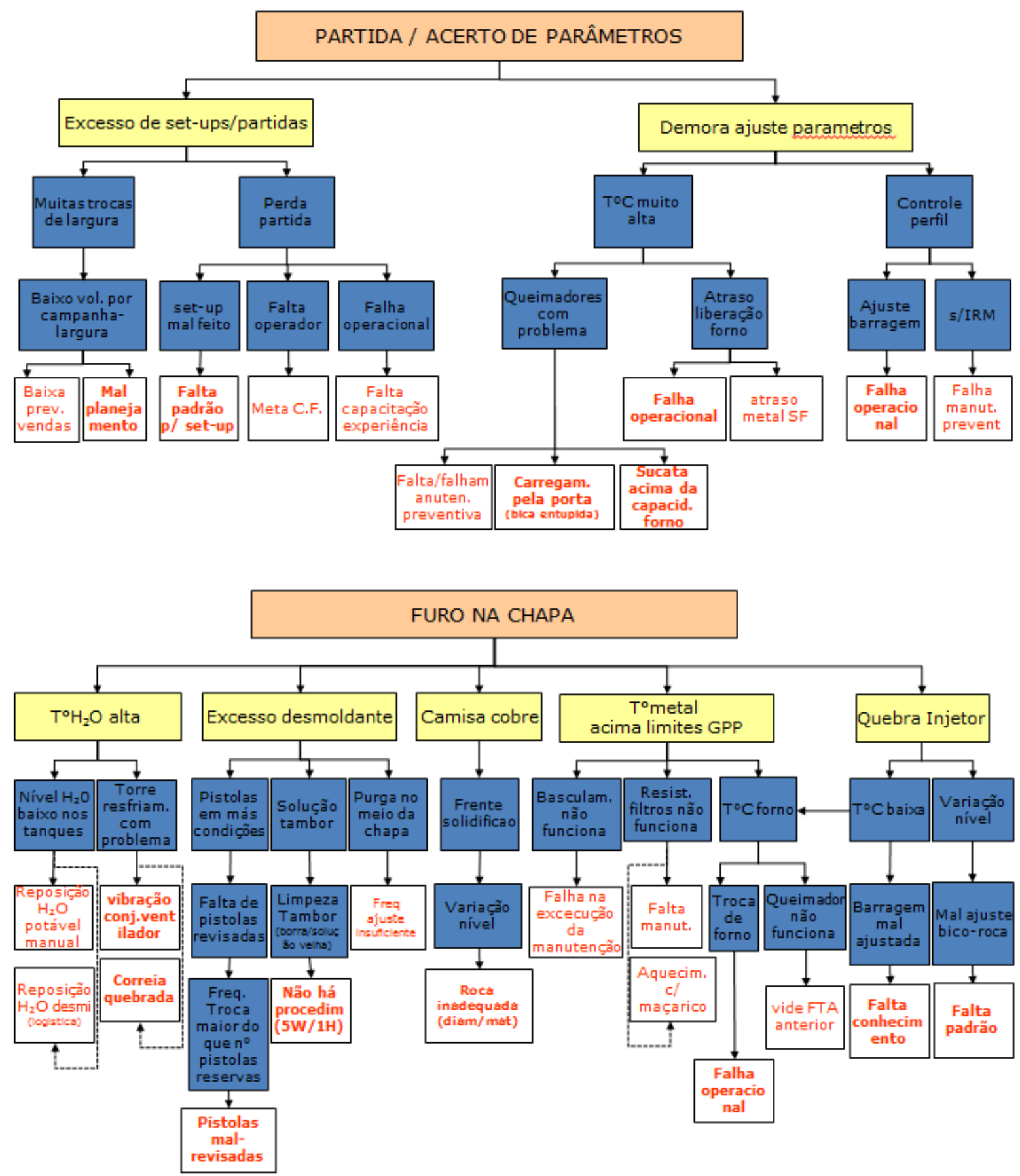

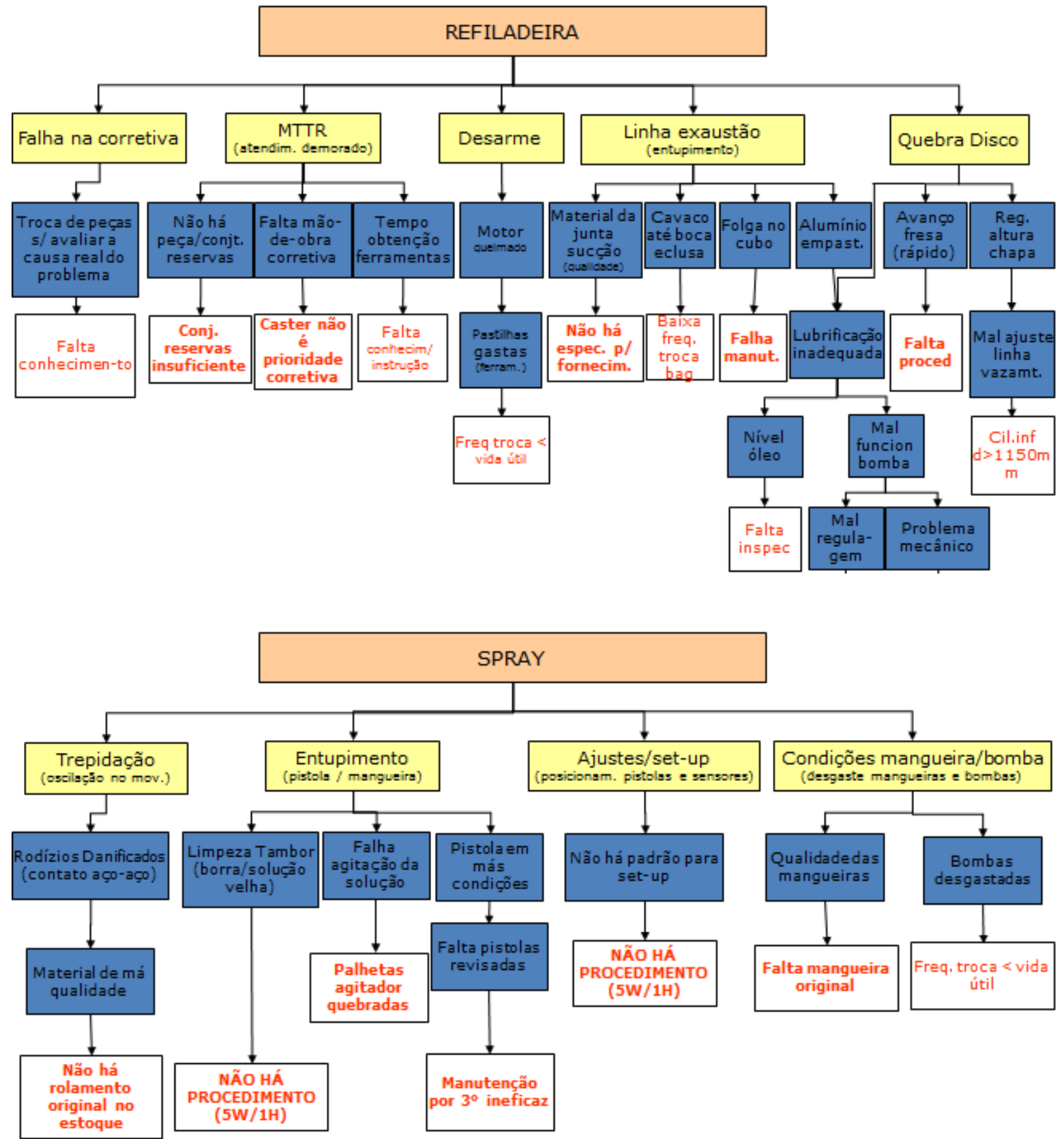

Figura 5. Diagrama de árvore de falhas para os 4 principais motivos de sucateamento de rolos.

Após a execução do plano de ações, verificamos que houve uma melhora sensível no Rendimento Metálico, conforme ilustrado na Figura 6. 
Boxplot of Rendimento Metálico Casters 7-12

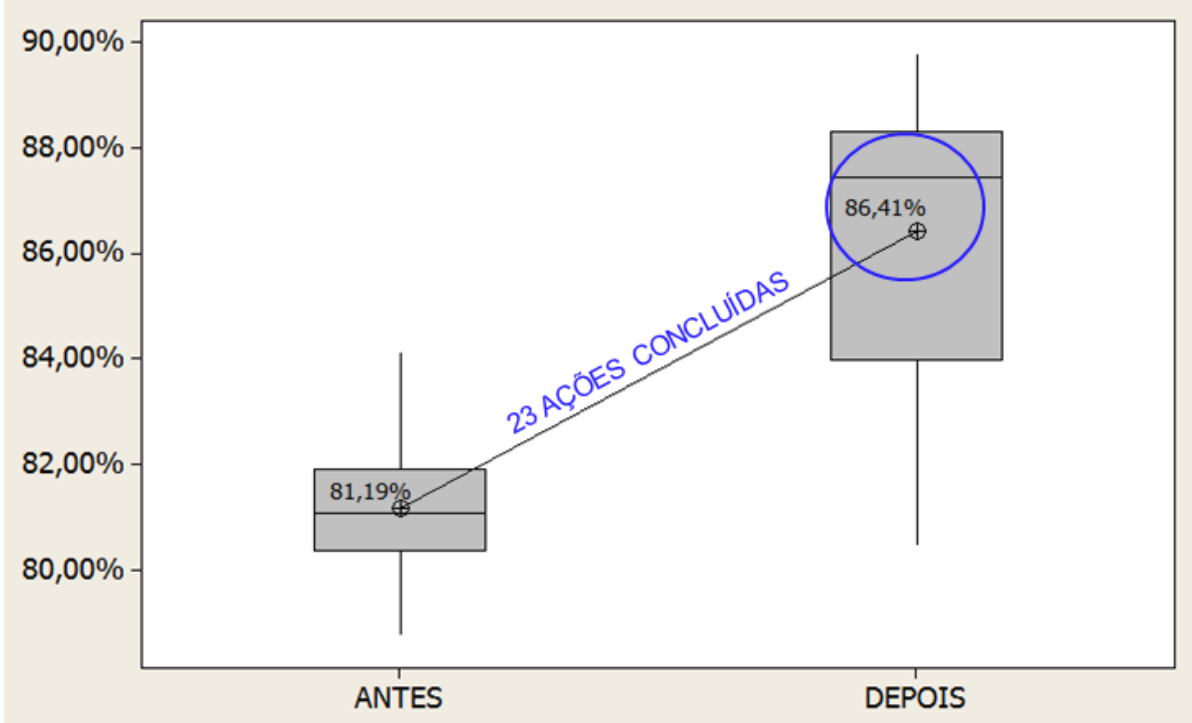

Two-sample I for RM C7-12

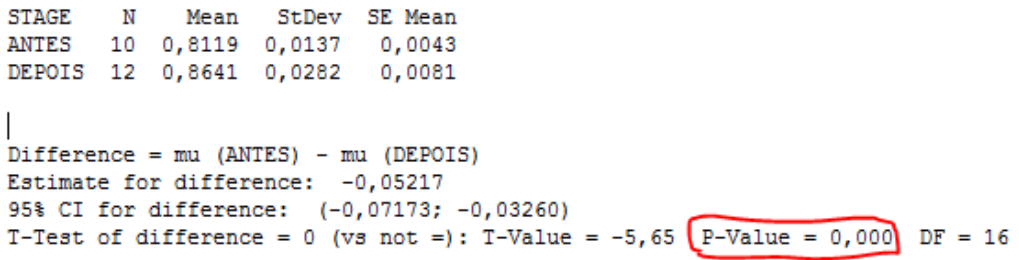

Figura 6. Boxplot do RM antes e depois do plano de ações, e teste de hipótese 2-sample-t.

Estes resultados indicam que devemos rejeitar a hipótese nula e que, portanto, podemos afirmar, com $95 \%$ de confiança, que o RM está maior do que antes do projeto.

A Capabilidade de Processo que estava em -0,91 antes do projeto (Figura 3), saltou para 0,42 .

\section{Capabilidade Final - Rendimento Metálico}

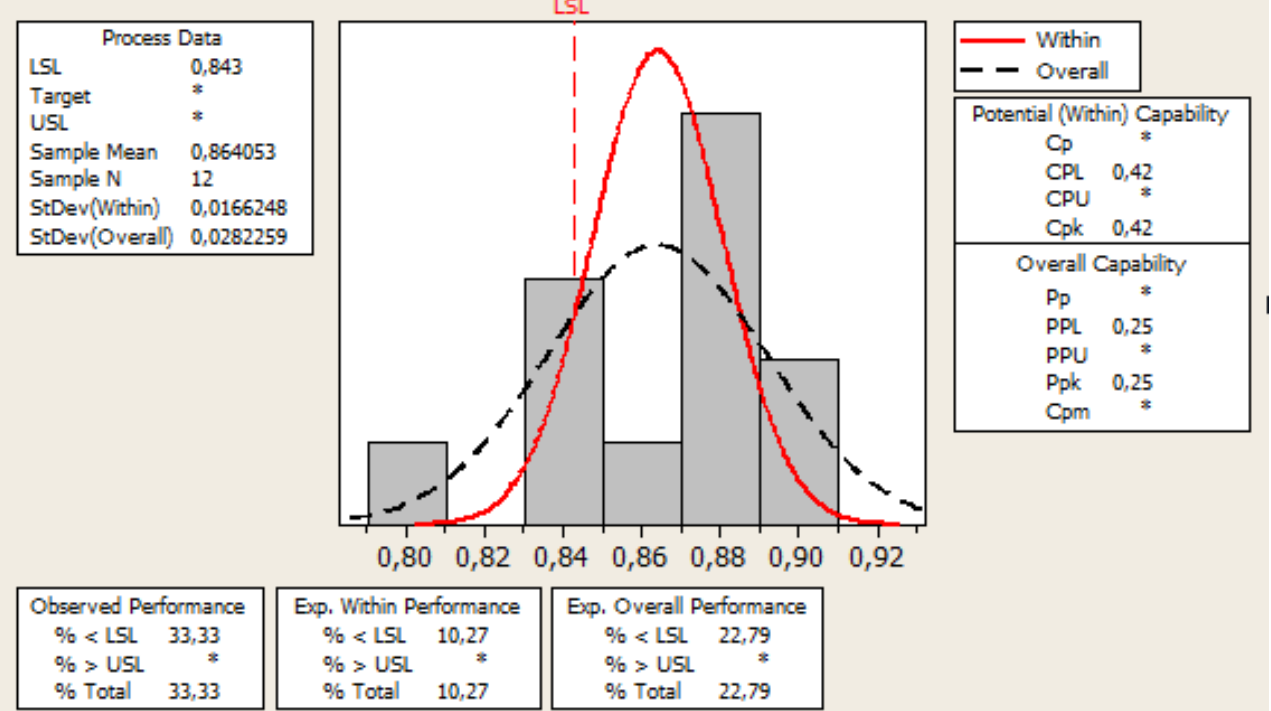

Figura 7. Análise da capabilidade de processo após a conclusão das ações de melhoria. 


\section{CONCLUSÃO}

A eficiência e o nível de performance do processo de vazamento contínuo pôde ser melhorado através de uma abordagem rápida e simplificada do ciclo DMAIC.

A redução da sucata gerada no processo, reduziu o custo de produção contribuindo para uma maior rentabilidade dos materiais produzidos nos casters largos da CBA.

\section{Agradecimentos}

Agradecemos à Votorantim Metais por nos conceder a autorização e oportunidade para apresentação deste trabalho.

\section{REFERÊNCIAS}

1 HARRY, M.; SCHROEDER, R. Six Sigma: The Breakthrough Management Strategy Revolutionizing the World's top Corporations, Doubleday, 2000.

2 BASSON, F.; BOSCH, M.; CHARLIER, P. Mastering the strip geometrical tolerances with the twin-roll continuous strip-casting technology. Light Metal, 2008: 715-720. 